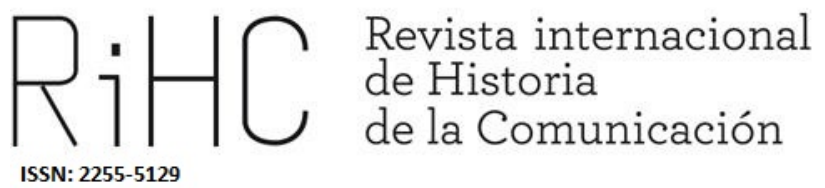

\title{
ONDAS INFORMATIVAS: SURGIMIENTO DEL PERIODISMO RADIAL EN COLOMBIA (1930-1948)
}

Informative waves: beginning of radio journalism in Colombia (1930-1948)

DOI: http://dx.doi.org/10.12795/RiHC.2019.i13.10

Recibido: 08/09/2019

Aceptado: 01/12/2019

Publicado: $15 / 12 / 2019$

Christian David Acosta Silva

ORCID (iD) 0000-0002-8274-7575

Universidad Minuto de Dios, Colombia

christianacosta.silva@gmail.com 
Resumen: La radio llegó a Colombia en la década de 1930, gracias a la iniciativa de diferentes radioaficionados que tenía Colombia (Pareja, 1984:17). Aunque desde el principio se encontró con muchos limitantes para poder expandirse, consolidarse y mantenerse a lo largo del tiempo. No obstante, tan pronto se crearon las primeras emisoras como la HJND y la Voz de Barranquilla en 1930 se inició la creación distintos géneros radiales, entre ellos los periodísticos. (Castañeda, 2017).

Desde el artículo que se encuentra a continuación, se exponen los hechos más significativos en el nacimiento de géneros periodisticos en la radio colombiana; sucesos que sin duda impulsarían una mayor búsqueda y consolidación de este tipo de espacios en medios sonoros.

Palabras clave: Radio periodismo, Emisoras colombianas, Primeras emisoras, Radio Reporteros, Noticias en radio

\begin{abstract}
Radio arrived in Colombia in the 1930s, thanks to the initiative of different radio amateurs that Colombia had (Pareja, 1984: 17). But from the beginning it encountered many limitations in order to be able to expand, consolidate and maintain itself over time. However, as soon as the first stations were created like the HJND and La Voz de Barranquilla in 1930, began the creation of different radial genres, among them the journalistic ones. (Castañeda, 2017).

From the article that follows, the most significant events in the birth of journalistic genres in the Colombian radio are exposed; events that would undoubtedly promote a greater search and consolidation of this type of space in sound media.
\end{abstract}

Keywords: Radio journalism, colombian radio stations, first radio stations, radio reporters, radio news.

\title{
Introducción
}

En junio de 1935, el cantante argentino Carlos Gardel se encontraba realizando una serie de conciertos en Colombia. Realizó uno en Bogotá (el 23 de junio) y el lunes 24 de junio se desplazaría, desde la capital hacia Cali, en un avión F31 de la empresa Saco y cuyo dueño y piloto era Ernesto Samper Mendoza. Dicho vuelo tuvo que hacer una escala en Medellín para abastecerse de combustible (Páramo y Lara, 2012), pero a las tres de la tarde y luego de iniciar vuelo en la ciudad paisa ${ }^{1}$, el avión que transportaba a Gardel colisionó con 'El Manizales' - avión de la Scadta ${ }^{2}$ - y produjo un incendio que en pocos minutos consumió por completo las dos aeronaves (El Tiempo, 1935:11). Colombia se estremeció con una de las noticias más trágicas de dicho año: la muerte del denominado

\footnotetext{
${ }^{1}$ Paisas: Término con el que se denomina a los habitantes y/o elementos provenientes del departamento de Antioquia y la región del Eje Cafetero (incluye departamentos como Risaralda, Quindío y Caldas).

2 Scadta: Sociedad Colombo-Alemana De Transporte Aéreo. Fue la primera aerolínea fundada en Colombia y en América y cuyas operaciones iniciaron en 1919. Fue una asociación entre cinco empresarios colombianos y tres alemanes hasta su desaparición en la década de los cuarenta cuando fue creada la aerolínea Avianca. (Revista Confidencial, febrero 11 de 2014) Recuperado de: http://www.banrepcultural.org/blaavirtual/revistas/credencial/febrero-2014/volando-magdalena
} 
'zorzal criollo' ${ }^{3}$. Todo el siniestro ocurrió ante la atónita mirada de las personas que estaban presentes en el aeropuerto 'Las Playas'. El suceso se llevó la vida de Gardel, varios de sus compañeros y reconocidas personalidades que se encontraban allí, entre ellos el abogado Estanislao Zuleta Ferrer (Téllez, 1974:31).

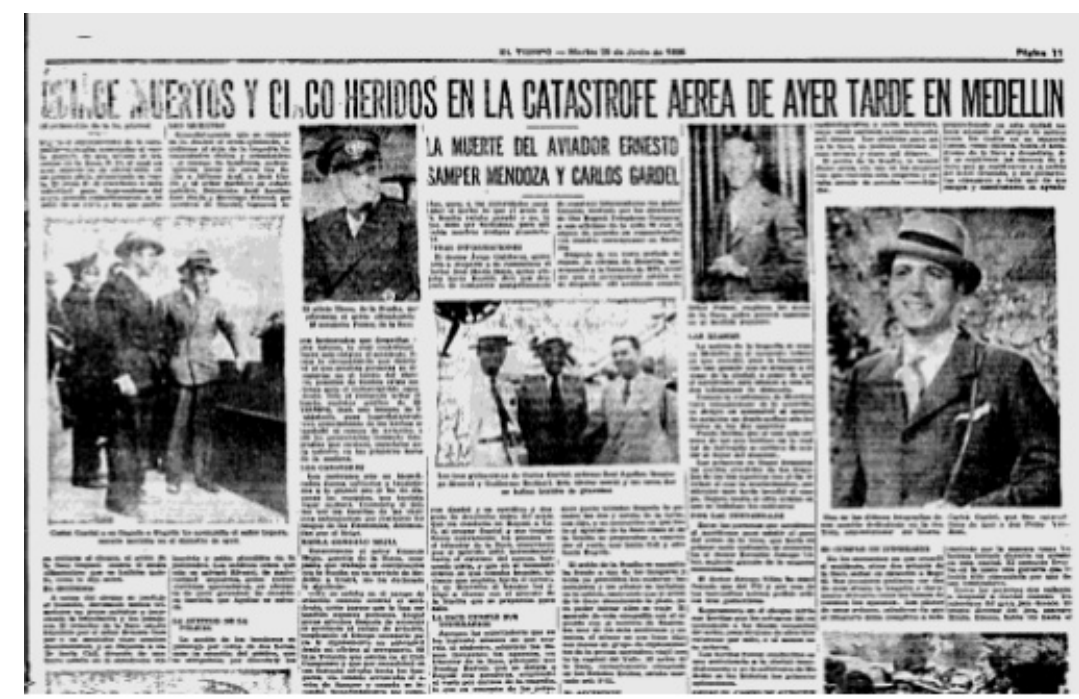

El Tiempo, 25 de junio de 1935, 11.

La catástrofe aérea dejó un saldo de quince personas muertas y cinco heridas, causó conmoción en todo el mundo que, a partir de la información brindada por las autoridades y los medios de comunicación, se enteraron de la magnitud de la tragedia ocurrida en tierras antioqueñas. Sin embargo, este hecho no solo pasaría a la historia como uno de los accidentes más trágicos en materia aérea y comercial, sino que ocasionó en el país la llegada del concepto de noticia a las emisoras colombianas, gracias a la labor de Antonio Henao Gaviria, quien cubrió periodísticamente el suceso y lo informó a todo el país por medio de La Voz de Antioquia y las emisoras que con el pasar de los minutos se irían conectando (Páramo y Lara, 2012). Lo anterior fue posible por la labor emprendida por el periodista tan pronto sucedió la catástrofe:

Henao Gaviria “acudió velozmente al aeropuerto y por su propia iniciativa principió a comunicar por teléfono todos los detalles del accidente trágico que Gustavo Rodas Isaza pasaba al aire de forma inmediata por La Voz de Antioquia, siendo así los primeros en informar al país y al mundo, en acción del más genuino radio periodismo, sobre la luctuosa tragedia aérea, que en su momento fue el más grande desastre de la aviación comercial mundial" (Téllez, 1974:31).

Es por ello por lo que, a partir de 1935, se crearon los primeros radio-periódicos o secciones informativas en las jóvenes emisoras existentes en la década de 1930 en Colombia. Lo anterior significó la creación de un género clave en la programación radial y la etapa siguiente que tuvo esta (Pareja, 1984:31), sin mencionar la oportunidad que

\footnotetext{
${ }^{3}$ El Zorzal Criollo, sobrenombre que le fue dado por el argentino José Betinotti en 1908, en honor al canto del pájaro que tiene dicho nombre y a la voz de Gardel (La Nueva.com, 24 de junio de 2010).
} 
le llegó a la radio para producir información propia y de asumir con responsabilidad su rol informativo independiente de otras fuentes de noticias como la prensa.

Hechos como este y otros que se darían años más adelante generarían los primeros indiciones de labores periodísticas en producciones radiofónicas. Teniendo en cuenta esto, el artículo quiere demostrar cómo las producciones radiofónicas de índole periodística se fueron creando y consolidando en la medida que las emisoras fueron madurando sus procesos de producción y emisión y no como momentos fortuitos que se dieron dando en distintos momentos de la historia.

Este trabajo es resultado de una investigación que manejó una metodología cualitativa, histórica y documental. Para ello, en una primera fase, se realizó una recolección documental de los textos, artículos o ponencias que trataron temas radiofónicos en sí mismos, buscando abordajes desde distintas perspectivas sobre el nacimiento y consolidación de los géneros periodísticos en algunas emisoras colombianas. Este material documental se convertiría más adelante en la materia prima y fundamental de la síntesis que se realizaría en el momento de redactar el presente artículo. Después, por medio de entrevistas a académicos que han estudiado la materia como los profesores e investigadores Nelson Castellanos, Catalina Castrillón y José Patrocinio Castañeda. Además, se realizaron entrevistas a locutores que trabajaron en medio del proceso de consolidación de diversas cadenas radiales que actualmente existen en Colombia.

Sin embargo, dado que nuestra investigación retomaba los inicios de la radiodifusión colombiana, no fue posible ubicar locutores que hayan trabajado en las nacientes estaciones radiales, porque en su mayoría han fallecido (teniendo en cuenta que el nacimiento radial colombiano fue hace ochenta años). En último lugar, realizamos la síntesis historiográfica que llevó a la redacción del presente artículo. En él presentamos los hallazgos que ubicamos en este proceso investigativo y realizamos el balance respectivo de la información que logramos ubicar.

Para no desbordar el tema, esta investigación abordó únicamente publicaciones académicas, artículos científicos y documentos sonoros que mencionaran el trabajo de las emisoras ubicadas en Bogotá, Cali, Medellín y Barranquilla (como ciudades principales de Colombia) entre 1929 y 1950. Periodo en el que se dieron los primeros intentos los primeros episodios de producción radiofónica (en su mayoría de forma aficionada).

Ahora bien, plantear una investigación sobre los inicios de un segmento específico en la radiodifusión colombiana como lo es el comienzo de los géneros periodísticos en las emisoras nos demuestra un inconveniente general que se presenta en cada investigación que se emprende en este campo: la recopilación de fuentes y archivos sonoros que daten de la época. Esta situación se convierte en un obstáculo para llegar a 
comprender desde una primera fuente la manera en que se ejecutaba alguna actividad radiofónica. La ausencia de este material ha impedido escuchar actualmente, por ejemplo, la narración del accidente de Gardel que se mencionó al inicio de esta introducción. La grabación más antigua a la que tuvimos acceso data de 1946 propiedad de la Radiodifusora Nacional de Colombia (hoy Radio Nacional de Colombia).

En cuestiones bibliográficas y académicas, la radio cuenta con distintas investigaciones que la han abordado desde distintos ejes, perspectivas o problemáticas. En panoramas generales y sin profundizarse en algunos segmentos específicos (en ciertos casos). Encontramos autores como Reynaldo Pareja, quien en 1984 hace la publicación de un libro que recupera los primeros cincuenta años de la radiodifusión en Colombia y nos ayuda a establecer indicios que permitan abordar nuestro tema de una manera adecuada. Hernando Tellez (1974) también realiza una recopilación valiosa para el estudio histórico y académico de la radio en Colombia al publicar su libro Cincuenta años de radiodifusión que recupera memorias de todos los aspectos que involucran a la radiodifusión colombiana desde el técnico, el relacionado con los contenidos, hasta la audiencia que tenían en su momento.

Por otro lado, en la academia se ha investigado el tema de distintas maneras y nos han dado diferentes perspectivas en el momento de continuar con nuestra investigación. Autores como Nelson Castellanos y sus artículos La radio colombiana. Una historia de amor y olvido (2001); El precio de un pecado: oír radionovelas a escondidas (2006) y el libro La radio del tercer milenio. Caracol 50 años (1998) es un gran exponente en la materia. Igualmente, tenemos casos como Maryluz Vallejo quien por medio de una de sus obras A plomo herido. Una crónica del periodismo en Colombia (1880-1980) (2006) da un panorama del periodismo tanto a nivel escrito como a nivel sonoro, que nos puede dar algunas luces del estado actual de la investigación radiofónica en materia periodística.

No obstante, la investigación de temas radiofónicos con enfoques hacia los géneros periodísticos presentes en ellos no se ha abordado de una manera profunda. Los autores anteriores realizaron sus investigaciones desde planos más generales (como el desarrollo de todos los formatos radiofónicos, incluyendo el de géneros periodísticos). Esto crea la necesidad de impulsar una investigación que establezca, por lo menos, los primeros vestigios de radioperiodismo en nuestro país, para comprender un poco más las posibles etapas que este pudo haber tenido a lo largo de estos ochenta años.

Por ello, el siguiente documento expone por medio de cuatro episodios, el recorrido que tuvieron las emisoras colombianas al momento de crear sus espacios informativos. El primero se titula "Los primeros pasos: llegada de la radio a Colombia (1930-1935)". Menciona y recopila cómo fueron los primeros años de radiodifusión en Colombia, desde la apertura de la primera emisora en el país - la HJN - en 1929, hasta el decreto que restringía el uso de las noticias de la prensa en las emisoras colombianas expedido 
en 1934. Con este apartado se intenta cumplir con el primer objetivo específico de la investigación: identificar los principales hitos históricos que motivaron el cubrimiento periodístico y la construcción de un espacio de información en las emisoras colombianas.

En segundo lugar, encontramos el episodio titulado "El Mensaje, el nacimiento de la noticia radial (1935-1940)", que recupera la creación de los primeros radio periódicos realmente estructurados y la manera en cómo la radio adquirió cierta independencia de la prensa, qué características obtuvo y cómo, a partir de este hecho, inició un proceso de consolidación en sí, siguiendo el objetivo de examinar las emisoras y personajes que pudieron desarrollar en cierta medida las características de un programa periodístico en Colombia.

Continuando con el escrito, ubicamos el apartado "La consolidación de las noticias: el nacimiento de las Cadenas (1940-1950)", que exhibe la manera en que la creación de las grandes cadenas radiales contribuyó a la consolidación del género periodístico en la radio de nuestro país y cómo la expansión radiofónica permitió la construcción de más espacios noticiosos, espacios que venían ganando terreno desde la década inmediatamente anterior. Además, menciona la forma en que se contaban los hechos en distintas emisoras colombianas. Con este logramos examinar las emisoras y personajes que pudieron desarrollar en cierta medida las características de un programa periodístico en Colombia y comprender la forma en la que se realizaba periodismo en radio durante la década de 1930 y la de 1940, así como su influencia y diferencias con el actual.

Por último, en las conclusiones se retoman los apartados principales de cada uno de los episodios mencionados anteriormente y se comparan con la manera en la que se llegó a hacer periodismo en la radio colombiana décadas más tarde, como 1960, 1970 y 1980. Con ello, se evidenciaría las diferencias que tuvieron los espacios informativos durante los treinta y algunas décadas después con la incursión de los primeros egresados de las facultades del periodismo en el país.

\section{Los primeros pasos: llegada de la radio a Colombia (1929-1935)}

Desde 1923, Colombia tuvo sus pasos más significativos en comunicación inalámbrica (y su infraestructura) con la apertura de su primera estación telegráfica internacional Morato -, ubicada en el entonces municipio de Engativá, estación que fue inaugurada por el presidente Pedro Nel Ospina (Pareja, 1984:18). Sin embargo, en ese año un grupo 
de radioaficionados, motivados por traer nuevas formas de comunicación al país, trajo a Colombia receptores y transmisores de baja potencia (Pareja, 1984:17). Durante toda la década del veinte, como afirma la investigadora Catalina Castrillón, "la iniciativa de personas interesadas en estos temas y que estaban enteradas de cómo se estaba desarrollando en otras partes del mundo, comenzaron a experimentar con la construcción de equipos de transmisión y recepción de mensajes, a agruparse en clubs de radioaficionados y a cuestionar al gobierno por la falta de un servicio de radiodifusión en el país".

Teniendo en cuenta eso, iniciaron pruebas experimentales de transmisión por onda radial, pero sin llegar a estructurar una emisora radial determinada o con programación establecida, como sostiene el profesor Nelson Castellanos: "antes del 1929, hay casos experimentales de jóvenes. Por ejemplo, aquí en Bogotá, en Chapinero, había cinco casas que emitían empíricamente, jugaban a la radio". El gobierno, viendo la oportunidad de tener una voz oficial diferente a la prensa, decide en 1924 solicitar los primeros equipos de onda larga y establecer su primera estación radiofónica, instalándolas en el sector de Puente Aranda, en Bogotá, cinco años más tarde (Pareja, 1984:18). De esta manera, el 5 de septiembre de 1929, fue inaugurada en Bogotá la primera emisora estatal (concebida como un órgano de difusión del gobierno) (Castrillón, 2011a:117). Además, durante el siguiente año, el gobierno inició la entrega de licencias, dándole un estatus legal a la radio, lo que significó el inicio formal de la radiodifusión en Colombia (Castellanos, 2016).

La emisora HJN, de corte público y estatal, inicia con una programación rica en temas culturales y académicos, tanto que en décadas más tarde (como en los noventa o inicio de los 2.000) "se retransmitían audios de temas académicos realizados por la planta docente de la Universidad Nacional", por ejemplo (Cuesta, 2012a:108).

No obstante, como se ha mencionado hace un momento, la llegada de la radio a Colombia obedeció principalmente a intereses particulares e individuales que se apasionaba por el auge de este medio de comunicación en otras partes del mundo. Incluso, este interés particular respondió a la conformación de espacios de intercambio de historias liderados por los clubes de radioaficionados que surgían entre la década de los veinte y los treinta (Castrillón, 2011a:115). Esta situación ocurrió en la gran mayoría de emisoras que surgieron a partir de este momento, incluyendo incluso las de corte universitario como las LAUD Estereo, de la Universidad Distrital en Bogotá o UN Radio de la Universidad Nacional de Colombia. La mayoría de estas emisoras "no han nacido como iniciativas institucionales sino como resultado de proyectos individuales" (Gaviria, 2017:9).

Tan pronto iniciaron las transmisiones de la HJN, se expandió el fenómeno de la radiodifusión en el país; tanto así, que Elías Pellet Buitrago creó la primera emisora comercial de Colombia: "La HKD o conocida más tarde como 'La Voz de Barranquilla', 
cuyas emisiones empezaron el 8 de diciembre de 1929" (Pareja, 1984:18). No obstante, estas emisoras hasta ahora estaban estructurándose, como afirma José Patrocinio Castañeda, "emitían música clásica, conciertos con música sinfónica, pero sus emisiones eran muy cortas, no eran las 24 horas como se ve actualmente". Lo anterior, es resultado de un proceso de desarrollo experimental de la radio, dada la inexperiencia de sus dueños, quienes iniciaron las emisiones como un pasatiempo, ya que eran sus directores, locutores y operadores, sus temáticas variaban según el interés del propietario de la emisorea (Castrillón, 2011a:117). Comparándola con el trabajo que se realizaría décadas más tarde en emisoras como la UN Radio, se mezclaría la programación académica e informativa con productos de corte musical como la Franja de Rock que es una propuesta alternativa en todos los esquemas programáticos que tenemos actualmente y que cumple 20 años de emisión (Cuesta, 2012a:110).

De igual manera, la radiodifusión colombiana durante la década de los treinta enfrentó grandes problemas de índole económica, técnica y normativa. En cuanto al factor económico, las familias no tenían los recursos necesarios para comprar un receptor a principios de los treinta dado a su elevado costo (Benítez, Isaza \& Mesa, 2009:37). Esto estimuló la costumbre de escuchar radio de manera colectiva. Por otra parte, el factor técnico fue un impedimento para un desarrollo más acelerado de Colombia en materia radial, ya que entre 1929 y 1935 eran muy pocos los transmisores, dada a su tecnología novedosa y poco conocida (Castellanos, 2016). Además, la escasa normatividad al respecto ocasionó una actividad aún más experimental y no se tenía certeza de los alcances que podría llegar a tener (Castrillón, 2016).

Ahora bien, los anteriores inconvenientes no fueron impedimento para el desarrollo y la construcción de las primeras parrillas de programación existentes en la radio, quienes, viendo la aceptación por parte de la comunidad desde su llegada, iniciaron la transmisión de programas de distintos estilos como los programas de concurso, radionovelas, radioteatro, las emisiones de música clásica y por supuesto los radioperiódicos (Benítez, et al., 2009:39).

Como sostiene el locutor Jimmy García, el formato líder en las primeras emisoras que aparecieron entre 1929 y 1931 fueron los programas con enfoque musical: "se emitían conciertos de música clásica, sinfónica y en algunas ocasiones se dedicaban al radioteatro". Con lo anterior, podríamos asumir cuál era el público especializado que tendría la radio, tanto en los locutores que construían los programas como en los oyentes que se dedicaron el algún momento a escucharla, por la afinidad que llegaron a tener con este tipo de programas. Un ejemplo de ello, fue la programación que se emitió por La Voz de Barranquilla el 8 de diciembre de 1929 (su primera transmisión): 
- "El Espectro de Oro. Obertura por la orquesta dirigida por Emirto de Lima4.

- Aria de Bach, ejecutada en el violonchelo por Guido Perla, acompañado al piano por Emirto de Lima.

- "Cuentos de Hoffman" por Cipriano Guerrero y su grupo de orquesta.

- "Serenata de Otros Tiempos", solo de mandolina por Hugo Perla.

- "Égloga del Mar" - Pasillo de Emirto de Lima ejecutado en el violonchelo por Guido Perla y acompañado por el autor.

- Crónica de Paco Lince, leída por Eduardo López Cabrales.

- "Perseverancia", por Cipriano Guerrero y su orquesta.

- "Salmo de amor", pasillo de Emirto de Lima, ejecutado al piano por Carlos. M. Zagarra.

- Himno Nacional de Colombia, ejecutado al piano por Carlos M. Zagarra, acompañado por la orquesta" (Téllez, 1974:14).

Fuera de este tipo de programación o de alguna transmisión especial, también se realizaban programas habituales que contenían "datos metereológicos, información bursátil, noticias tomadas algún diario local" (Castrillón, 2011a:118).

En contraste, a medida que la audiencia radial fue aumentando, se incrementó la necesidad de transmitir hechos noticiosos vía sonora, por lo que a medida que se fueron creando y organizando ciertas estaciones radiales, también fueron apareciendo espacios dedicados a la información y la noticia. Es por eso que un empresario con conocimientos básicos de técnica sobre radiotransmisores se aventuró en 1930 a transmitir periodísticamente varios eventos: Enrique Ramírez.

Ramírez, un radioaficionado recién Ilegado de Camden, Estados Unidos se arriesgó al transmitir "experimentalmente la posesión del presidente Enrique Olaya Herrera ocurrida el 7 de agosto de 1930 y los festejos conmemorativos del centenario de la muerte de Simón Bolívar, que se celebraron en Manizales el 17 de diciembre de ese año" (Téllez, 1974:20). Estas transmisiones fueron posibles gracias a que usó un radiotransmisor hecho por él mismo, ayudándose con la utilización de líneas telefónicas y parlantes distribuidos estratégicamente por el sector (Pareja, 1984:23). Partiendo de estos dos hechos, la programación informativa en la radio fue aumentando paulatinamente hasta crear los radioperiódicos, espacios en los que "la audiencia tuvo la oportunidad de informarse acerca de lo que estaba sucediendo a nivel local pero también a nivel mundial" (Páramo y Lara, 2012).

Asimismo, estos espacios informativos nacieron desde la inexperiencia de los dueños de las emisoras o aquellos que tenían los recursos para comprar un espacio en alguna

\footnotetext{
${ }^{4}$ Emirto de Lima fue un compositor, pianista y musicógrafo nacido en 1890 (probablemente) en Curazao (Antillas holandesas) que estudio en gran profundidad el folclor colombiano hasta su muerte ocurrida en Barranquilla en 1972. (La Opinión de Granada, 18 de septiembre de 2005.)
} 
estación. Por ello, durante la primera mitad de la década de 1930, la figura del radioperiódico se dedicó a leer noticias (principalmente de la prensa) frente al micrófono y la audiencia de la emisora en cuestión (Cuesta, 2012b). Décadas más tarde pasaríamos a la figura en la que el "reportero puede consignar en una cinta magnética la voz del protagonista de la noticia y hacer un directo desde una línea de telefonía fija" (Cuesta, 2012c). Esto significaría y nos da un panorama de la evolución que tendría este tipo de programas.

Como el programa informativo se reducía a la lectura del periódico frente a un micrófono, frecuentemente se incurría en equivocaciones en plena emisión, como confirma Jimmy García: “muchas veces se cometían errores por parte de los locutores porque iban leyendo y encontraban frases como sigue en la página siguiente o cómo se ve en la fotografía y ellos al estar concentrados leían la frase". De igual manera, este formato "permitía el despliegue de la información y el tratamiento periodístico de una forma similar a como se hacía en los periódicos escritos" (Latorre, Muñoz, Montoya \& Vásquez, 2008:55).

En algunas emisoras como la HJN, la programación informativa consistía en la construcción de boletines diarios sobre noticias de gran envergadura:

La información como función propia de la radio sirvió en ese entonces para la actualización de los acontecimientos que se produjeron en el marco de la Guerra con Perú ocurrida en 1932. De igual forma, estos boletines eran emitidos de forma ocasional - no regular - y se alternaba con música brillante. La emisión se hacía desde las seis y media o las siete de la noche aproximadamente y extendía por dos horas. (Lara y Páramo, 2012).

La Guerra con el Perú, igualmente, fue el mismo motivo por el que se iniciaron las primeras transmisiones periodísticas en el departamento de Antioquia, de la voz de Gustavo Rodas Isaza:

Él (Rodas Isaza) inicia transmisiones en 1932, como parte de las variedades que ofrece la emisora Ecos de la Montaña, la primera radio comercial establecida en Medellín, y 'cuenta' las incidencias del conflicto bélico entre Colombia y Perú, con noticias de lo sucedido con una semana o más de retraso. (Velásquez, 2007:4).

En consecuencia, estos casos son considerados antecesores de lo que posteriormente se conocería como radio periodismo y una semilla de lo que aún más adelante se convertiría en periodismo radial consolidado. En sus inicios, se utilizó el término radio periodismo -y no periodismo radial - dado a que implicaba tanto el uso de la radio como medio de transmisión como de la prensa como fuente de información y noticias (Lara y Páramo, 2012). 
Lo anterior ocasionó un fuerte conflicto con la prensa, que llevó el caso hasta procesos judiciales, al ver afectados sus intereses económicos y comerciales. Los dueños de los grandes periódicos del país pelearon y objetaron la labor que realizaban múltiples radioperiódicos del país, ya que sin inversión ni reconocimiento alguno leían directamente las noticias registradas en los medios impresos.

De igual manera, como sostiene el profesor Carlos Cantor, "la radio era más espontánea en comparación con la prensa, era más fácil llegar a la audiencia cuyo único trabajo que tenía que hacer era escuchar". Esto representó una clara desventaja a los medios impresos, quienes tenían costos elevados en la producción de su ya consolidado formato informativo.

Sumando a esta situación, la radio era más aceptada en la comunidad que tenía mayores dificultades para acceder al medio impreso, ya sea porque no tenía el dinero para comprar alguna edición o porque no sabía leer (teniendo en cuenta que más del $50 \%$ de la población colombiana no sabía ni leer ni escribir) (Páramo y Lara, 2010) lo que generó una mayor desventaja por parte de la prensa en sí.

En consecuencia y gracias a la influencia que ejercían algunos grupos socioeconómicos en la política del país y la presión que hicieron a través de algunos periódicos existentes (Pareja, 1984:33), lograron que el presidente de la República, Enrique Olaya Herrera, y el Ministro de Correos y Telégrafos, Alberto Pumarejo, expidieran el Decreto 627 del 23 de marzo de 1934 que restringió la publicación en radio de noticias originadas desde los periódicos, y solo autorizó la emisión de noticias de este tipo, a partir de las doce horas de transcurridas la emisión primaria de esta. Las emisoras que incurrieran en dicha práctica tendrían que pagar una multa de cincuenta pesos de la época. Tan pronto se expidió el Decreto, las reacciones de varios columnistas no se hicieron esperar, entre ellos Fray Lejón. El periodista (Citado por Rincón, 2010:19) afirmó en su editorial de EI Tiempo que:

"todo periodista ve con entusiasmo el justo Decreto que el gobierno ha dado, para que la prensa no la saquee la radio. Yo personalmente he antipatizado con aquel imbécil invento del diablo (la radio) que llena la casa de anuncios baratos, de discursos viejos y chistes malos". 


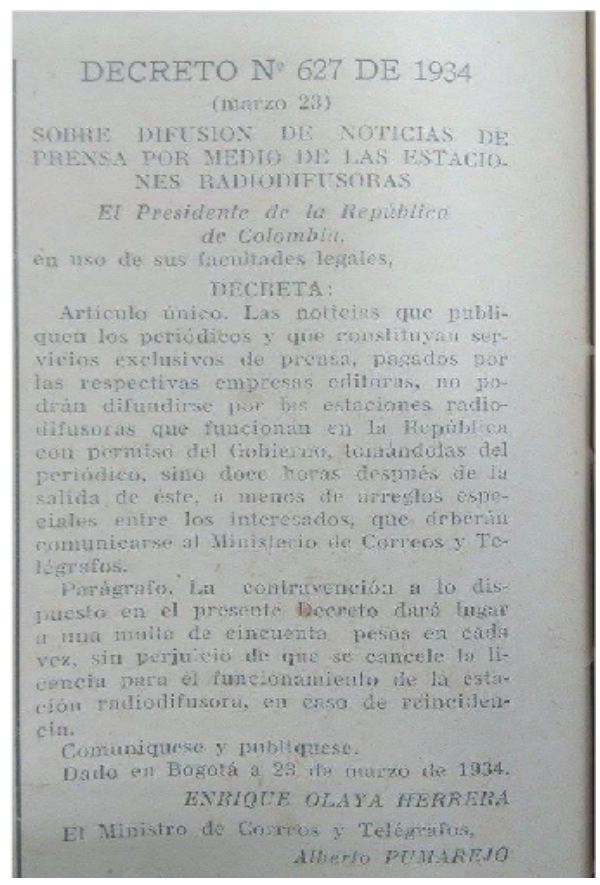

A causa de esto, las emisoras se vieron obligadas a generar bloques de noticias propios. La radio colombiana inicia un proceso de reestructuración informativa, apropiándose de la figura del 'reportero' y afiliándose a las grandes agencias de noticias y emisoras internacionales, para enriquecer su contenido en el plano internacional, en especial en la segunda parte de la década de los treinta, momento en el que distintos países tendrían gran repercusión mediática. (Benítez, et al., 2009:41). Aun así, determinados sucesos que sacudirían ciertas regiones de Colombia también estimularían la creación de radioperiódicos que más tarde tendrían tanto afiliación política como económica, aparte de la ampliación de la noticia hablada a la noticia comentada.

\section{El mensaje, el nacimiento de la noticia radial (1935-1940)}

En 1934, el presidente liberal Alfonso López Pumarejo “fundó el radio periódico La revolución en Marcha, como el lema de su primer gobierno (1934 - 1938), transmitido por la estación La Voz de la Víctor y dirigido por Raimundo Aguirre. Con este programa se intentaba expandir su proyecto político" (Benítez, et al., 2009:41). Ejemplos como este, reflejan el tinte político que se incrustó en el radio periodismo colombiano. Esto debido a que, con la expansión de la radiodifusión en el país, los partidos políticos vieron la oportunidad para difundir sus aspiraciones políticas, dado a la creciente audiencia que 
tenía la radio. En el caso de López Pumarejo, por ejemplo, el liberalismo vio la oportunidad para seguir afianzando sus convicciones, siendo este el segundo mandato liberal, luego de la hegemonía conservadora de todo el primer tercio del siglo XX.

El radio periódico se estableció como un espacio que oscilaba entre los quince y veinte minutos en el que se mezcló información con opinión (Castellanos, 2016). Una muestra de este tipo de radio periódico fue Noticiero Orientación. La tribuna de la patria, dirigida por Juvenal Betancur (hermano del presidente Belisario Betancur). Dicho espacio informativo y de opinión era, en palabras de Jimmy García, muy beligerante, deseoso de marcar un hito y eminentemente conservador en concordancia con la línea editorial de la emisora La Voz de Colombia propiedad del Partido Conservador.

Sin embargo, no todos los periódicos tuvieron algún tipo de afiliación política y en 1935 llegaría el concepto de noticia a las emisoras del país. La muerte de Carlos Gardel y la primera transmisión en vivo desde los micrófonos de La Voz de Antioquia que ya contaba con Gustavo Rodas Isaza y al recién llegado Antonio Henao Gaviria significó la llegada formal del concepto de noticia en radio. El 24 de junio de 1935, Colombia y el mundo entero se estremecieron con la noticia de la muerte trágica del cantante de tango, Carlos Gardel. Zuleta (citado por Velásquez, 2007:3) afirma que "desde el barrio Manrique de Medellín de vio una bola de candela como un sol anaranjado y humeante", era la colisión y posterior incendio del F31 y El Manizales, dos trimotores que estaban en el aeropuerto 'Las Playas' de la capital antioqueña. En el siniestro se llevó la vida del zorzal criollo y gran parte de su comitiva musical, el abogado Estanislao Zuleta Ferrer, el piloto y empresario Ernesto Samper Mendoza, entre otras personalidades.

Antonio Henao Gaviria acababa de llegar al país luego de adquirir un bagaje periodístico en Estados Unidos, como él mismo mencionaría en una entrevista otorgada a Gloria Valencia en 1985 (citado por Velásquez, 2007:8), fue "cronista judicial de El Gráfico, un periódico bilingüe ubicado en New York". Por coincidencia, él se encontraba en el aeropuerto justo en el momento del siniestro, por lo que decide llamar a La Voz de Antioquia y emitir junto a Gustavo Rodas Isaza los hechos del accidente, lo que sería considerado como la primera transmisión en directo fuera de los estudios de una emisora. Por ese cubrimiento periodístico, Medellín fue pronunciado con "asombro y consternación por personas de las naciones e idiomas más distintos" (Lara y Páramo, 2012).

Por otro lado, desde la emisora antioqueña se logró por primera vez la conexión en cadena de distintas emisoras colombianas, ya que a través de enlaces telefónicos se enlazaron entre sí, La Voz de Antioquia, Ecos de la Montaña y Emisora Philco (Latorre et al., 2008:55). 


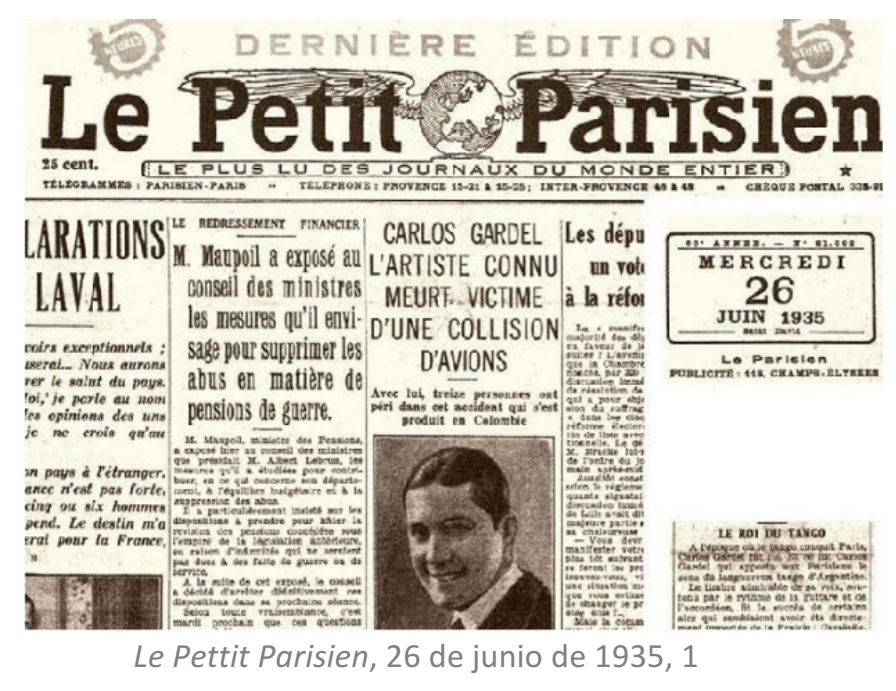

La radio logró lo que la prensa no había podido hacer y emitió de manera espontánea una noticia, lograron técnicamente montar la noticia (Cantor, 2016) y mediante este desafortunado evento, instaurar la figura del reportero en radio, un profesional que se dirigiera al lugar de los hechos y transmitiera desde allí los acontecimientos que estaba mirando. Esta noticia internacional marcaría un nuevo rumbo de información en adelante.

En consecuencia, se creó el radioperiódico El Mensaje, dirigido por Rojas Isaza y con la innata colaboración de Henao Gaviria. Iniciaron transmisiones el lunes 15 de julio de 1935 (Latorre, et al., 2008:54), tres semanas después de la transmisión del siniestro aéreo ocurrido en Medellín. Con este programa Henao Gaviria realizaría una carrera periodística de gran prestigio y admiración por el seguimiento de este y más hechos que cubriría posteriormente (Téllez, 1974:32).

Sin embargo, esta labor fue eminentemente informativa y se dedicó, prácticamente de manera exclusiva, a difundir la información directamente a cómo llegaban desde sus fuentes, remitiéndose únicamente a sus hechos puntuales. Cuestión que se diferenciaría a cómo se ejerce periodismo radial actualmente en el que encontramos a un "profesional de análisis, no un simple informador, dado que ese papel lo puede cumplir cualquier ciudadano gracias a los diferentes canales por las innovaciones tecnológicas" (Cuesta, 2012c:14).

Por otro lado, comparándolos con contextos internacionales, este tipo de formatos radiofónicos llega prácticamente una década más tarde a territorios colombianos: el primer programa radiofónico de corte noticioso e informativo tuvo lugar en Estados Unidos en 1923 por el periodista Bill Slocum que emitió, través de la WJZ (actualmente, la WABC) de New York, boletines de 15 minutos que resumían los hechos publicados en los diarios de la prensa estadounidense (Uribe, 2019). Un formato similar que se da 12 años después en Colombia. 
Paralelamente, se configuró una nueva forma de contar los hechos que suceden en determinados lugares del país, logrando transmitir la información correctamente sin la necesidad de recurrir a otras fuentes de información como la prensa. Así como El Mensaje llegó a tener gran repercusión en toda la región antioqueña, aparecería años más tarde su primera competencia, surgida desde Emisora Philco, cuyo programa se llamó El Micrófono y su conductor fue el paisa Pedro Duarte. Por medio de este programa se siguen los aspectos técnicos que tuvo El Mensaje por lo que gran parte de sus programas contaron con "transmisiones en directo desde diferentes sitios" (Latorre, et al., 2008:55). A estos dos programas se le sumarían más tarde Amerindia, El Pregonero y Últimas Noticias.

Por otra parte, en Medellín no solo se desarrolló el radioperiodismo rápidamente después de 1935, otras ciudades como Cali y Bogotá iniciaron sus propios productos periodísticos independientes y novedosos.

En Cali, por ejemplo, se fundó el radioperiódico llamado Noticias y Comentarios, que se transmitió por La Voz del Valle desde el 29 de noviembre de 1936 y cuya trayectoria llegó a tener más de un cuarto de siglo (Benítez, et al., 2009:44). La constitución de este programa fue una de las primeras experiencias de rigurosidad y reflexión periodística, ya que los libretos preparados para la emisión de cada programa eran redactados y corregidos antes de su emisión al aire. Benítez, Isaza y Mesa (2009) recopilaron los temas que eran tratados normalmente en cada programa de Noticias y Comentarios:

La programación del radioperiódico era bastante miscelánea y serpenteaba por diferentes ámbitos: discusiones sobre información política, económica y judicial, chismes punzantes, crítica partidista, escándalos públicos, campañas educativas cívicas y morales, notas sociales sobre las personalidades más insignes de la ciudad y hasta algunos apuntes curiosos y cómicos. No obstante, más allá de estos ámbitos especialmente locales, el radioperiódico igualmente abrió espacios en los que discutió temas de carácter regional, nacional e internacional. Esta última dimensión recobró especial trascendencia en coyunturas tan significativas como la Guerra Civil Española o la Segunda Guerra Mundial (2009:46).

De esta experiencia se resalta su carácter y postura regional, una característica que estuvo presente en la radio colombiana en sus inicios. No obstante, según los registros mencionados por Benítez, Isaza y Mesa, las emisoras vallecaucanas y en especial La Voz del Valle llegaron a tener posturas provincialistas, teniendo en cuenta el contexto de la región: un sector en vía de desarrollo, cerrada en sí mismas y con una carga política heredada del siglo anterior (Benítez, et al. 2009:47).

Por otro lado, en la capital del país se desarrollaron formatos radio periodísticos de la mano del emprendedor y empresario Enrique Ramírez (fundador de RCN Radio) que mediante el cubrimiento de ciertos eventos políticos y deportivos propulsó el género en 
algunas emisoras de la ciudad. En 1938, el país vivía una fuerte polarización política que

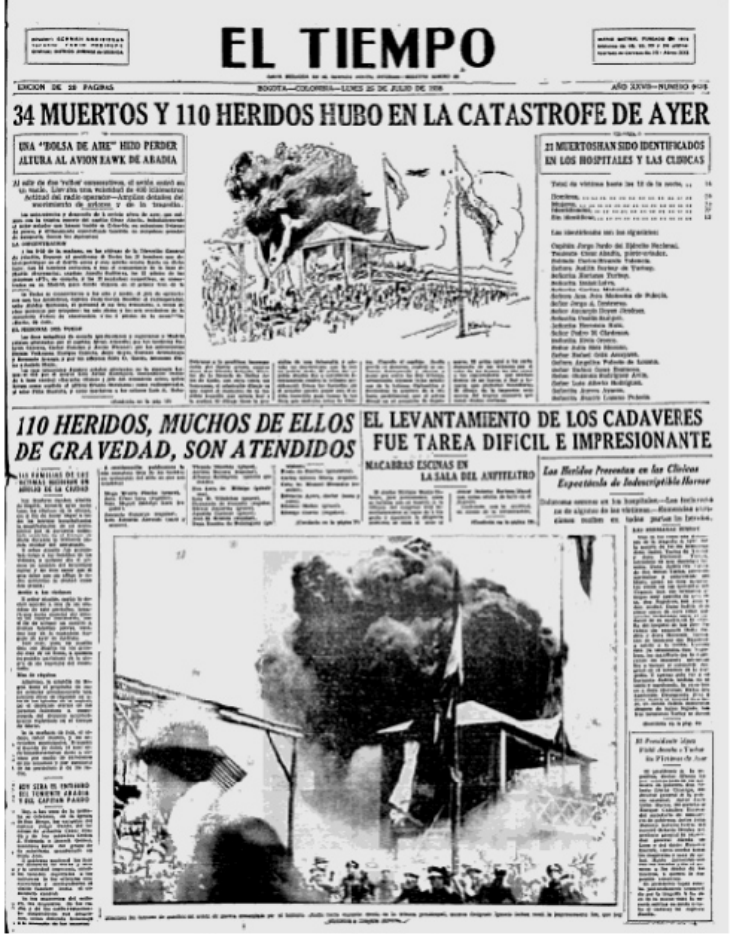

El Tiempo, 25 de julio de 1938, 1 involucraba una fuerte represión por parte del gobierno de López Pumarejo a todo síntoma de oposición (Castrillón, 2011a:123). Sumado a esto, en agosto de este año se celebraría el aniversario No. 400 de la fundación de Bogotá y se celebrarían los primeros juegos bolivarianos lo que da una nutrida agenda informativa en la que la radio vería su oportunidad de brillar con estos eventos:

Había que transmitir esos eventos para que los públicos latinoamericanos pudieran seguir su desarrollo al minuto. Enrique Ramírez con sus compañeros técnicos se entregaron a la tarea de preparar debidamente a la emisora Nueva Granada para tal ocasión. Instaló puestos

fijos en los estadios, para transmitir por líneas telefónicas tendidas por su cuenta hasta los estudios de la Calle 16. (Téllez, 1974:42)

Por esta razón, se evidencia que el inicio del radioperiodismo en Bogotá fue muy similar al de Medellín. La capital con la celebración de su cuadringentésimo aniversario de fundación y la realización de las primeras justas bolivarianas se convertirían en la oportunidad de consolidar el radioperiodismo bogotano. Con la participación de emisora Nueva Granada, emisora pionera en Bogotá, se logró generar una experiencia positiva en el oyente que sin duda tuvo más facilidades para obtener la información sobre las noticias que más le interesaron en materia deportiva. El plano periodístico, el informativo y el deportivo siempre han tenido desde el inicio de la radio una estrecha relación, que se han consolidado con el pasar de los años y ha evolucionado en distintos formatos radiofónicos (Uribe, 2019).

Con la experiencia de La Voz de Antioquia en Medellín, Nueva Granada en Bogotá y La Voz del Valle en Cali, se estableció el punto de partida para la consolidación del periodismo radial en Colombia. Mediante la búsqueda y creación de espacios noticiosos en las crecientes emisoras - y posteriores Cadenas - se establecería un formato informativo claro y concreto.

Ahora bien, a finales de la década del treinta e inicios de los cuarenta, la agenda informativa y la reportería tendrían protagonismo en los espacios radio periodísticos del país, ya que el cubrimiento se realizaría en vivo por medio de conexiones telefónicas. Es así como en 1938, Emisora Nueva Granada realizaría la transmisión de la noticia sobre 
la tragedia aérea que ocurrió en el Campo de Marte, ubicado en el barrio Santa Ana, Usaquén al norte de Bogotá. Luego de una revista militar realizada en el campo le siguió una muestra aérea que podrían disfrutar los 20.000 asistentes al evento. Pero al medio día y luego de transcurrir gran parte de la exhibición aérea, uno de los pilotos perdió el control de su aeronave y se precipitó sobre la tribuna en la que se encontraba gran parte del público (Caicedo, 1991) y reconocidas personalidades del ámbito político como el saliente presidente Eduardo Santos, el electo mandatario Alfonso López Pumarejo e incluso el joven (y presidente décadas más tarde) Misael Pastrana. (Téllez, 1974:60).

Después de sucedido el fatal siniestro, la emisora Nueva Granada realizó una transmisión de la misma forma en cómo La Voz de Antioquia la hizo con la noticia de la muerte de Carlos Gardel tres años atrás. Es decir, valiéndose de controles remotos transmitió a la audiencia capitalina la tragedia sucedida al norte de su ciudad.

Al día siguiente, se tenían 34 muertos y 110 heridos después de la catástrofe (El Tiempo, 25 de julio 1938:1). No obstante, con el pasar de los días la cifra de fallecidos fue aumentando de manera dramática: para el 26 de julio (dos días después) la cantidad de víctimas eran 47 (EI Tiempo, 26 de julio de 1938:1); 51 para el 27 de julio (EI Tiempo, 27 de julio de 1938:1) y 56 para el 29 de julio (El Tiempo, 29 de julio de 1938:1). Al final, en la tragedia llegaron a perecer 74 personas (Caicedo, 1991).

De igual manera, los conflictos bélicos que se desarrollaron alrededor del mundo tendrían cabida en el tratamiento de las noticias de cada uno de los radioperiódicos que se emitían hacia 1939 como la Guerra Civil Española y la Segunda Guerra Mundial. Sin embargo, dado al alto costo que representaba la producción y establecimiento de un periodista y/o corresponsal en territorios internacionales, las emisoras por aliarse con las agencias internacionales de noticias. Por ello, "la primera agencia que suministró el servicio a una emisora colombiana fue la AP, que desde 1937 ofreció noticias a la HJN" (Pareja, 1984:51).

Asimismo, estos hechos bélicos junto a los episodios relacionados con la inestabilidad política presente en Colombia ocasionaron que las estaciones radiales se convirtieran en verdaderos vehículos de carga ideológica. Por esta razón, el gobierno decidió tomar cartas en el asunto y el 5 de septiembre de 1939 expide el decreto 1771 que reglamenta y promueve que las emisoras tuvieran una línea neutral en sus transmisiones, dada la postura que asumió el gobierno frente al conflicto que se desarrollaba en el viejo continente (Pareja, 1984:49). Además, el gobierno en cabeza del presidente, Eduardo Santos; el Ministro de Gobierno, Carlos Lozano, y el ministro de Correos y Telégrafos, Alfredo Cadena, regularon el idioma en que se transmitieran las noticias (únicamente podían emitirlas en castellano) y recomendó sumo cuidado en las noticias que se emitieran sobre las naciones en conflicto (Diario oficial, 12 de septiembre de 1939:775). 
En síntesis y finalizando este apartado podemos evidenciar que ciertos eventos especiales acaparaban la atención de los locutores y operadores de distintas emisoras del país que incluso lograban estimular la transmisión en cadena estos hechos (Castrillón, 2011a:119). El caso de Mario Carvajal marcó un record en las regiones de habla hispana, debido a que logró transmitir en la madrugada del 10 de febrero de 1939, la noticia sobre la muerte del Papa Pío XI ocurrida en Ciudad del Vaticano. Dicha transmisión sería la primera realizada en Colombia (se emitió por la Voz de Antioquia) e incluso fue el primero en contar la noticia en español, haciéndolo tres minutos antes que la estación XEW de México (Téllez, 1974:74).

Casos como el anterior, demuestra la vocación que tenían los profesionales en radio para la construcción de sus programas periodísticos y conforme al paso de los años, los irían consolidando, generando contenidos de una mejor calidad y mayor alcance. Además, temas como el deporte siempre moverían audiencia tanto en su etapa de consolidación comercial y organización como en el momento de las grandes cadenas radiales tuvieron un fuerte auge. Cada ciudad le dedicó un espacio de cubrimiento a los deportes:

La Voz de Antioquia transmitió los partidos de fútbol en el hipódromo de los libertadores. Nueva Granada (Bogotá) emitió los primeros de juegos bolivarianos y Ondas de la Heroica realizaría programas transmitiendo partidos de béisbol, deporte muy famoso en la región caribe colombiana. (Téllez, 1974:76).

La radio sin duda representa, al finalizar la década de los treinta, un factor fundamental en la cotidianidad colombiana. Poco a poco fue llegando como un medio alternativo para buscar información, diversión o distracción. De ahí en adelante, dependería de los empresarios dueños de las estaciones radiofónicas la consolidación de estos espacios y ampliación de los mismos. Por ello el nacimiento de las cadenas radiales daría origen a los espacios necesarios para conformar equipos especializados y que fortalecerían formatos como el periodismo informativo, las secciones deportivas y las radionovelas.

\section{La consolidación de las noticias: el nacimiento de las cadenas (1940-1950)}

Iniciando la década de 1940, el radioperiodismo seguía su evolución frente a las adversidades y cantidad de noticias que surgían tanto a nivel nacional como internacional. Uno de los sucesos que tuvo mayor trascendencia mediática tanto en la prensa como en la radio del país fue la Segunda Guerra Mundial (1939-1945). Para ello, 
desde principio de los años cuarenta, se recurre por primera vez a los contenidos noticiosos que se emitían a través de las Agencias de Noticias Internacionales.

En contraste, la radio aprendió de dicha experiencia con los servicios informativos de Estados Unidos y vio la necesidad de imitar el modelo que algunos locutores habían examinado en el país norteamericano. Casos como el de José Santos y Hernando Téllez, quienes visitaron las instalaciones de CBS, ayudaron a completar el modelo que querían seguir. (Téllez, 1974:47).

Por otra parte, en gran parte de las emisoras muchos radioperiódicos - por no decir todos - no eran propiedad de la emisora por la cual se emitían, sino que eran espacios arrendados por sus propietarios para asegurar la estabilidad económica de la estación radial (Téllez, 1974:65) sin contar, claro está, de los espacios publicitarios que eran vendidos para la época.

Después de haber pasado por una época de experimentación fuerte y de consolidación empresarial, las emisoras ya estaban posicionándose como un medio de comunicación con gran cantidad de adeptos en cada una de las regiones en las que hacía presencia. Por ello, los radioperiódicos ya hacían parte de la programación habitual de las emisoras y ya contaban con una audiencia robusta (Páramo y Lara, 2012). Lo anterior llamó la atención de periodistas que estaban vinculados en periódicos de distintas partes del país y académicos e intelectuales que vieron en la radio una ventana para construir contenido distinto y alternativo. Esto se dio gracias a que la prensa entendió que la radio no era una competencia directa, sino que sería su complemento (Castellanos, 2016).

Si bien, en ese entonces las estaciones radiales tenían buena acogida en la población que cada vez estaba creando hábitos alrededor de escuchar determinados programas de algunas emisoras, estas aún no contaban con audiencias masivas dada a la dificultad para acceder a aparatos radiofónicos. Afortunadamente, décadas más tarde, el acceso a la información es mucho más sencillo, rápido y directo; tanto así, que el papel del periodista va más allá del registro de los acontecimientos sino pasa a un rol mucho más investigativo, propiciando los espacios de discusión política de aspectos que afecten a determinado lugar (Cuesta, 2012c:18).

Aun así, los programas periodísticos tuvieron un alcance muy local dado a la limitada cobertura que tenían las emisoras, debido a la mala calidad que en ocasiones tenían las antenas y antes los problemas que tenía la onda corta. Pero, a partir de la idea de distintos empresarios, surgió la propuesta de enlazar varias emisoras a lo largo del país y así expandir la difusión de cada programa emitido y llegar con programas de distinta índole a diferentes lugares de Colombia.

El primer intento de generar una cadena de emisión se remonta a 1937, cuando Enrique Ramírez: 
emitía diariamente un programa que se replicaba al mismo tiempo por Nueva Granada en Bogotá; La Voz de Antioquia en Medellín; La Voz del Valle en Cali; Emisora Electra en Manizales; Radio Santander en Bucaramanga y Emisoras Fuentes en Cartagena. Pero duró muy poco por deficiencias técnicas y falta de patrocinio comercial. (Pareja, 1984:52).

Este intento efectuado por Ramírez en 1937 se une a varios realizados durante la década de los cuarenta, años en los que se logra una consolidación empresarial de las cadenas. En distintos autores se denota como esta década se convierte en la era dorada de la radio; siendo así que se constituye "una especie de circuito radial que tuvo sus epicentros en Bogotá y Medellín" (Castrillón, 2011b:144)

Finalizando la década de los cuarenta surgen las primeras cadenas radiales como RCN y Caracol en 1948, como resultado de la alianza entre diferentes empresarios y algunos radioaficionados que había en el país para la época como Fernando Londoño Henao y Enrique Ramírez (Castellanos, 2016). Muchos autores determinan el nacimiento de estas dos cadenas como el inicio formal del periodismo radial, apartándose del concepto de radioperiodismo.

Un hecho ocurrido a mediados de los años cuarenta también evidenciaría la fuerte influencia que tendría la radio: el intento de Golpe de Estado de 1944. En la madrugada del 10 de julio, un grupo de militares retuvieron en la ciudad de Pasto al presidente Alfonso López Pumarejo, en un intento de derrocar al presidente e imponer un régimen militar. Sin embargo, en Bogotá tanto Alberto Lleras Camargo (Ministro de Gobierno) como Darío Echandía (Designado para la presidencia) controlaron la noticia en gran parte de la mañana, al medio día decidieron tomar control total de la radio y solo se pudieron emitir los boletines que eran enviados desde el palacio presidencial (Pareja, 1984:63). Fue tal el nivel de restricción que hubo en medios radiales y los mensajes enviados desde el gobierno que el pueblo mostró rápida y masivamente muestras de apoyo al presidente y estimuló a los militares para que desistieran de esa idea. El presidente confirmaría un día después que el país estaba en calma gracias a los boletines informativos que transmitió La Voz de Antioquia (Téllez, 1974:58). Este episodio demostró el poder de movilización y masificación que tiene la radio, influencia que quedó nuevamente expuesto cuatro años después con el asesinato de Jorge Eliécer Gaitán. En este tipo de situaciones se renueva y se expande el rol del oyente que pasa de ser un actor pasivo a ser uno actor activo dentro del proceso radial, además de establecer una relación periodista-ciudadano completamente abierta y permanente (Cuesta, 2012c:18).

De la misma manera en que la radio se expandía masivamente con el pasar de los años, los radioperiódicos y los noticieros radiales empezaban a tomar aún más fuerza, aunque el lenguaje que estos utilizaban siempre fue distinto a la forma de hablar de la población, ya que al basarse en la terminología que utilizaba la prensa sumado al paso de 
periodistas de los periódicos a pertenecer a las emisoras, las características con las que estos se expresaban migraron de igual forma a la radio.

Con esta migración, "se siguen suprimiendo los artículos. Los titulares son del tipo tarzán: hombre-mono-comer-carne. También se traslada el lead condensado y la estructura piramidal en el cuerpo de la nota" (López, 2000:161). Se conserva el estilo con el que se contaban las noticias en la prensa. Esto se evidencia en la forma en la que se narraban los hechos en emisoras como la Radiodifusora Nacional de Colombia:

"Noticias de noviembre de 1946:

- El 23 del presente hacia media noche, fue muerto con un disparo revolver Alberto Mariño en esta ciudad. Según datos hasta ahora recogidos trata de cuestión privada entre particulares.

- En Paipa, hacia las diez y media de la noche, un Cabo policía quiso requisar un ciudadano que promovía escándalos, resultó herido el chofer Armando Colorado y el cabo policía para defenderse numerosas personas atacaban con puñal.

- En Chiquinquirá se produjo en la noche un tiroteo en la plaza pública, resultando muertos los doctores Jorge Armando Cortés y gravemente herido su hermano Rogelio Cortés. Se estima que es labor criminal y antipatriótica, acusar a policías por delitos que no ha cometido, con el único objeto de sembrar caos, desconfianza y prevención contra los representantes de la autoridad.

- El Papa Pío XII, informan desde la Ciudad del Vaticano, que está completamente reestablecido en su salud. La enfermedad que aquejo al pontífice le impidió recibir en las vísperas de navidad al Colegio de Cardenales según la tradición a pesar de que no fue obstáculo para que pronunciara su alocución en esa fecha. El Papa no reanudará audiencia la semana entrante, cuando recibirá a los cuerpos diplomáticos" (Radio Nacional de Colombia, 1946).

También, años más tarde nacen radioperiódicos como Línea directa dirigida por Julio Nieto Bernal. El programa resumía las noticias más importantes del día y pasaban las voces de los personajes que habían sido protagonistas con las noticias del día y recopilaban las mejores declaraciones (Plata, 2017).

Aparte de esto, los espacios noticiosos estandarizarían el proceso por el cual construían los radioperiódicos, viéndose reflejado en los pasos previos que seguían en los informativos tanto de las décadas de 1940, 1950 y 1960. Por esta razón, se constituyeron los primeros cuerpos de redacción que construían las noticias desde un punto cero y luego se la pasaban al locutor, quien las leía al aire:

El proceso previo para la emisión de un noticiero era largo. De la sala de redacción salían y le entregaban a uno, sobre el escritorio, las noticias. Era muy complicado porque estaba con tachones, corregida y todo se veía en el papel, pero uno ya se defendía. Era un poco distinto a ahora porque no existía la técnica de hoy, 
solamente era de la máquina de escribir a la cabina de emisión. Lo leía uno con dificultad, pero con pericia. (García, 2017).

Pero muchas veces, el proceso se diferenciaba dependiendo del tipo de noticia que se necesitaba construir, dado a que la emisión de un hecho de fuente nacional podría ser más sencilla que uno de plano internacional:

Las noticias de afuera llegaban por un teletipo, que eran una especie de máquinas de escribir conectadas a una red y automáticamente iban presentando las noticias. Entonces uno recibía la noticia; sonaba una campanita que avisaba la llegada de una noticia y un sonido aún más alarmante cuando la noticia era de una extraordinaria importancia. Para la época había varias agencias de noticias como la AFP, la AP, EFE, entre otras. Cada agencia tenía su teletipo. (Plata, 2017).

Estos dos episodios dan cuenta de los esfuerzos que ya hacían las emisoras para establecer noticieros de alta calidad y cuya búsqueda de noticias implicara una verdadera labor periodística, ubicando los medios necesarios para conseguir los hechos, ya fueran de índole nacional o de tipo internacional. Las transformaciones de los cuerpos de redacción para emitir con gran credibilidad las noticias también forjaría más tarde la especialización de las fuentes: aparecen los especialistas en fuentes judiciales, en noticias políticas y otros en redacción económica (Castañeda, 2016). Esto ayuda a profesionalizar la radio y sus integrantes, antes de que ingresara la nueva generación de locutores, egresados en su mayoría de las primeras facultades de periodismo que tendría el país (Cantor, 2016).

Dada esta situación, muchos periodistas se vincularon a medios internacionales para adquirir mayor experiencia en la construcción de programas noticiosos, como la historia de José 'Pepe' Cubillos, quien se vinculó años después del nacimiento de las cadenas radiales a la estación La Voz de Estados Unidos, una de las primeras emisoras de habla hispana en el país norteamericano. La rigurosidad técnica y la trayectoria de este tipo de emisoras quedaban en evidencia en la forma en la que ellos trabajaban:

No podía demorarme más de dos minutos, ni menos de minuto y medio por nota. Dentro de la norma eran mínimo tres fuentes, lo que luego se convirtió en una regla de oro para todos. No podía hacer un reportaje basándome en lo que había escuchado en otra emisora. Todas las informaciones requerían de cierto tratamiento el asesinato de alguien, algún fenómeno natural, entre otros. (Cubillos, 2017).

Este tipo de experiencias enriquecieron a la radiodifusión colombiana. Es común encontrarse con el nacimiento de nuevas perspectivas periodísticas como los programas con alguna orientación política, editorial y beligerante. Particularmente, Contrapunto se convertiría en una nueva experiencia que introdujo en el país las noticias comentadas cuya construcción era "estricta y con una postura muy editorial" (Plata, 2017). Dirigido 
por Jaime Soto y los hermanos Eduardo y Lucas Caballero (Castellanos, 2016) presentaba un formato novedoso en el que básicamente dos o tres locutores leía un renglón del libreto, de modo que hacían un contrapunteo entre un locutor y otro, con un manejo de la información que llegó a alcanzar algún tinte de humor sin dejar de lado su fuerte tendencia política (García, 2017). Esa forma de contar noticias cautivó a la audiencia a tal punto que llegó a completar una audiencia estimada de cinco millones, un hito para la época en que se emitió (Lara y Páramo, 2012).

Conforme a experiencias como Contrapunto, la radio fue adquiriendo de manera explícita tintes políticos. Aunque es válida la aclaración, esta tendencia siempre estuvo presente en varios radioperiódicos que nacieron mediante la modalidad de arrendamiento de espacios en las estaciones radiales. Pero ahora la tendencia ya estaba presente en los radioperiódicos propios de la emisora. Muestra de ello, es el lenguaje que utilizan para narrar y analizar varios hechos, como los que hizo la Radio Nacional de Colombia, en el marco de la huelga petrolera que tuvo Colombia en 1946:

(...) Nosotros (la emisora) hemos sido los primeros en reconocer que la mejora del salario para ajustarlo a las condiciones actuales de los precios es una reivindicación justa. Pero los trabajadores deben tener mucho cuidado con lo que hacen, porque en cualquier momento resultan dando la sensación de que pretenden jugar con el país y entonces tendrán en su contra a la opinión... (Radio Nacional de Colombia, 19 de mayo de 1946).

La política al ser protagonista en las noticias colombianas en la radio, un hecho de este tipo, causaría gran revuelo y múltiples movilizaciones dentro y fuera la radio. Entonces, se demostraría la gigante capacidad de la radio para movilizar a la población al conocerse el asesinato del líder político Jorge Eliécer Gaitán, ocurrido a la 1p.m. del 9 de abril de 1948. Con este homicidio, gran parte de la población perdió la esperanza de un cambio que solicitaban para el entonces gobierno de Mariano Ospina Pérez. En medio de las revueltas que se desataron luego de confirmada la muerte del caudillo liberal, diferentes emisoras empezaron programación que cubriría desde distintos aspectos este hecho, pero muchas de ellas serían violentadas por algún motivo.

Juan Eugenio Cañavera trabajaba en Emisora Nueva Granada y tan pronto se confirmó la noticia del asesinato de Gaitán anunció que iniciaba un programa con música fúnebre en homenaje al fallecido líder, pero un grupo de reconocidos periodistas se tomó los estudios de la emisora y obligó a continuar la transmisión con la locución de políticos de izquierda, que incitaron a los desórdenes que se desencadenaron ese día (Téllez, 1974:90).

La radio informativa iniciaría una época nueva a partir de este evento. La censura a la que fueron sometidas las comunicaciones en la noche del nueve de abril (Pareja, 1984:69) contribuiría finalmente a la expansión de un nuevo método informativo por 
parte de las estaciones. La radio finalmente se convirtió en la "gasolina que incendió la ciudad y que encendió al país, cuestionándose fuertemente ¿cuál debería ser el papel real de la radio?" (Cantor, 2016). Además, en emisoras como la Radio Nacional se cambiaría la forma de contar noticias, cuya huella es la emisión de este día, dado a que el locutor "se dedicó prácticamente a arengar para que la gente saliera a lo que él llamaba 'vengar la sangre del caudillo', contribuyendo a los desmanes" (García, 2017).

Este hecho es importante analizarlo a mayor profundidad teniendo en cuenta que, al crearse las cadenas radiales, se reconfigura el quehacer informativo, dado que en la década de los cincuenta con la diversificación de los programas, nacería una carrera comercial y de prestigio por la cual muchos locutores se conocerían por sus voces como la de Armando Plata (2017) en el plano informativo, Jimmy García (2017) en el deportivo e informativo, José Cubillos (2017) en el plano internacional, entre otros.

De modo similar, décadas más tarde también llegarían más locutores y periodistas como Yamid Amat, Juan Gossaín, Armando Plata, entre otros (Cantor, 2016) que reconfigurarían nuevamente las secciones de noticias en radio y crearían nuevos precedentes para la consecución de hacer radio en la actualidad.

\section{Conclusiones, la historia hasta ahora comienza}

Es tangible reconocer la forma en la que nació el radioperiodismo en Colombia. A partir de accidentes y hechos que involucraron la solidaridad de los ciudadanos, la radio vio la oportunidad para surgir periodísticamente. Sin embargo, luego de plasmar los resultados alcanzados a nivel histórico y documental, se entiende cómo los géneros periodísticos llegaron a las estaciones radiales colombianas en medio de un proceso de consolidación que tuvo cada emisora en su momento. No fueron hechos aislados los que desencadenaron los vestigios con los que iniciarían los formatos informativos $y$ periodísticos durante la década del treinta y del cuarenta.

No obstante, es relevante destacar algunos hechos que si impulsaron en cierta medida el establecimiento de espacios informativos alrededor de la programación de algunas emisoras en ciudades grandes como Medellín y Bogotá. Casos como el accidente en el aeropuerto La Playas ocurrido en 1935 y la tragedia aérea de Campo de Marte en 1938 constituyeron contenidos de gran atracción para el público, que, viendo la facilidad de acceso a los programas, le dieron gran acogida al medio sonoro colombiano.

Por otro lado, sucesos como el Decreto promulgado en 1934 en el que se les prohibía la emisión o lectura de noticias provenientes de los medios escritos impulsó el 
establecimiento de más espacios de contenido informativo propio, madurando aún más el formato, en una curva de crecimiento paralela a la que tuvieron las emisoras y algunos de sus contenidos como los concursos, las radionovelas o los espacios musicales.

Otro aspecto que nos permite afirmar que los géneros periodísticos fueron ganando espacio en las diferentes programaciones radiales fue el relacionado con el crecimiento económico y organizativo de las estaciones radiales. Este proceso contribuyó al establecimiento de locutores que le dieron credibilidad a cada radioperiódico, que incrementó el éxito de este y atrajo a muchos periodistas de la prensa, quienes, al ver un nuevo estilo de emisión de noticias, migraron a la radio. Este hecho sin duda transformaría la forma de hacer y contar noticias. No sin dejar de lado transmisiones que se hicieron alrededor de la Guerra con Perú en 1932, el accidente de Carlos Gardel en 1935 o eventos deportivos fueron las primeras muestras de periodismo informativo en Colombia (Uribe, 2019), aspectos que fueron mencionados en varias ocasiones en este documento.

Igualmente, un aspecto que sin duda ayudó a la consolidación y maduración de espacios informativos radiales fueron las noticias y cubrimientos deportivos. A medida que fueron expandiéndose las emisoras, sus audiencias crecieron y los intereses de estas incrementaron en aspectos como los deportes, por ejemplo. Las transmisiones realizadas por La Voz de Antioquia desde el hipódromo de Los libertadores sobre los partidos de futbol (que hasta ahora daba sus primeros pasos en el ámbito profesional) llamaron la atención de la audiencia de Medellín (Téllez, 1974:76). Un modelo similar realizaría Emisora Nueva Granada con el cubrimiento que se realizó a los primeros Juegos Bolivarianos realizados en Bogotá que causaron furor en el público capitalino. Los dos eventos marcaron una tendencia que tendría la audiencia de ahí en adelante, una preferencia hacia el tema deportivo que aprovecharían las cadenas radiales décadas más tarde tanto para lograr contenidos informativos que atrayera cada vez más público. Esto se demostraría en situaciones que incluso sucederían décadas más tarde:

El cubrimiento que realizó Todelar al mundial de futbol realizado en Inglaterra en 1966 (García, 2017), la vuelta a Colombia en bicicleta durante la década de los cincuenta por parte de RCN (Castellanos, 2016) y el cubrimiento al recién conformado torneo profesional de futbol colombiano realizado por Gabriel Muñoz (2017) generaron gran repercusión por la novedad de escuchar en vivo y por medios radiales los eventos deportivos de mayor trascendencia en el país.

Ahora bien, se podría concluir que los hechos mencionados a lo largo de este estudio permiten dar los pasos iniciales en el establecimiento de los géneros periodísticos en las emisoras colombianas. Llegamos a la conclusión que distintos hechos fortuitos no fueron desencadenantes en la creación de espacios informativos, sino que estos se trataron acorde al momento de crecimiento y consolidación radial que vivía el país. 
La transmisión en vivo que realizó la Voz de Antioquia en la que informó al mundo sobre la muerte de Gardel en 1935, por ejemplo, se constituyó como uno de los primeros hitos de radio periodismo que tenemos en la historia nacional. El genuino periodismo ejercido esta fatídica tarde del mes de junio de ese año impulsó a Henao Gaviria a continuar con una pasión que lo interesaba desde años atrás y que no había aparecido de repente en medio del accidente. Fue el momento en que la radiodifusión colombiana tomó en cuenta las noticias y cambió de la radio espectáculo (Cantor, 2016) a una programación más estandarizada y con espacios informativos más serios y establecidos porque el proceso iba en este punto. Sí hubiera ocurrido años atrás quizás la transmisión no hubiera sido la misma, ni con la misma repercusión ni con el mismo resultado.

El factor político siempre ha estado -y estará- presente en los medios de comunicación colombianos. Desde el nacimiento de la prensa lo estuvo, desde la llegada de la radio igualmente y así mismo lo ha estado en la televisión. Sin embargo, en la radio, la política se vio particularmente beneficiada, ya que aprovechó la infraestructura radiofónica del país de manera tajante, lo que repercutió en la facilidad que tenía al transmitir oralmente sus discursos y sus ideologías, pero también contribuiría a una posible polarización en el país. El caso de la muerte de Gaitán en 1948 y el intento de golpe de Estado del presidente Alfonso López Pumarejo son muestra de ello. Lograron movilizar (o tranquilizar) a la audiencia gracias a la maniobra ejercida en cada evento.

Lo anterior se presenta como una oportunidad investigativa. Los periodistas y la radio ya iniciaron un camino entre 1930 y 1950, exploratorio y experimental, en el que se cometieron errores y aciertos, pero que evolucionó eficazmente y acorde al desarrollo del contexto colombiano. En pocas palabras, la historia del periodismo radial hasta ahora comienza. Nos queda por investigar mucho sobre que sucedió después de la década de los cincuenta con el establecimiento, fortalecimiento y expansión de las cadenas que innovaron en nuevos formatos que se meterían a cada hogar colombiano.

\section{Fuentes Primarias}

\section{Documentos oficiales}

Presidencia de Colombia. (13 de abril de 1934). Sobre difusión de noticias de prensa por medio de las estaciones radiodifusoras [Decreto 627 de 1934]. Diario Oficial de Colombia: 22558. 
Ministerio de Correos y Telégrafos. (12 de septiembre de 1939). Se dictan algunas medidas en el ramo de Telecomunicaciones [Decreto 1771 de 1939]. Diario Oficial de Colombia: 24167.

\section{Entrevistas}

Cantor. C. Comunicación Personal. Noviembre de 2016

Castañeda J. Comunicación Personal. Marzo de 2017

Castellanos. N. Comunicación Personal. Julio de 2016

Castrillón C. Comunicación Personal. Octubre de 2016

Cubillos. J. Comunicación Personal. Marzo de 2017

García. J. Comunicación Personal. Marzo de 2017

Plata. A. Comunicación Personal. Marzo de 2017

\section{Prensa}

CAICEDO, A. (17 de diciembre de 1991). "Clave 1938 Tragedia Santa Ana". El Tiempo. Recuperado de: http://www.eltiempo.com/archivo/documento/MAM-210270.

DEL PINO, R. (18 de septiembre de 2005): "Emirto de Lima, exuberancia caribeña". La opinión de Granada, p. 38.

"Quince muertos y cinco heridos en la catástrofe aérea de ayer tarde en Medellín". (25 de junio de 1935). El Tiempo, p. 11.

“Carlos Gardel l'artiste connu meurt victime d'une collision d'avions. (El artista conocido de Carlos Gardel muere víctima de una colisión de aviones)". Le Petit Parisien, 26 de junio de 1935, p.1.

“El pavoroso siniestro aéreo de Medellín”. El Tiempo, 26 de junio de 1935, p. 15.

"La muerte de Gardel provoca una verdadera racha de suicidios". El Tiempo, 27 de junio de 1935, p. 1.

"34 heridos y 110 muertos hubo en la catástrofe de ayer". El Tiempo, 25 de julio de 1938, p.1.

"La lista de muertos llegó anoche a cuarenta y siente". El Tiempo, 26 de julio de 1938, p. 1.

“A cincuenta y uno llegó ayer la lista de muertos". El Tiempo, 27 de julio de 1938, p. 19. 
"Fallecieron dos heridos del siniestro de Santa Ana". El Tiempo, 29 de julio de 1938, p. 2

\section{Referencias Bibliográficas}

BASE DE DATOS POLÍTICOS DE LAS AMÉRICAS. (1999). Colombia: Elecciones Presidenciales 1826 - 1990. Georgetown University y Organización de Estados Americanos. Recuperado de http://pdba.georgetown.edu/Elecdata/Col/pres1826 1990.html.

CASTRILLÓN, C. (2011a). Los radioaficionados como precursores de la audiencia radial colombiana, 1928-1940 en Revista Historia y Sociedad (No. 20). Universidad Nacional de Colombia (Sede Medellín), pp. 113-132.

- (2011B). La actividad radial colombiana a través de algunos periódicos y revistas, 1928-1950 en Revista Colombiana de Antropología (No. 47). Instituto Colombiano de Antropología e Historia (ICANH), pp. 137-154.

CUESTA, O. (2012a). Historia de la radio universitaria: estudios de caso de la emisora de LAUD Y UN Radio en Revista Ánfora 20 (No. 34). Universidad Autónoma de Manizales, pp. 97-115.

- (2012b). Historia de la locución radiofónica en Colombia: caracterización de unas posibles etapas en Revista de investigaciones UNAD (No. 11). Universidad Nacional Abierta y a Distancia, pp. 281-293.

- (2012c). Los axiomas de la radio, tecnología y periodismo radiofónico en Razón y Palabra (No. 81). Universidad de los Hemisferios, pp. 767-786.

GAVIRIA. (2007), La radio universitaria en Colombia en Revista 91.9, la revista que suena (No. 24). pp. 9-11.

GÓNGORA, A. (2017). Definición de periodismo interprestativo. Alexrgongora [Blog]. Recuperado de https://alexrgongora.wordpress.com/2014/02/02/definicion-deperiodismo-interpretativo/

ISAZA, A., BENÍTEZ, D., y VILLEGAS, A. (2009). Algunos rasgos de la historia de la radio en Cali y algunos aspectos de la historia de Cali en la radio: el caso del radio periódico 'noticias y comentarios' de 'La Voz del Valle' (1936 - 1939) (Tesis de pregrado). Universidad del Valle. Cali.

LA NUEVA. (2010). Gardel, la voz que cantará eternamente en Lanueva.com. Recuperado de http://www.lanueva.com/sociedad-impresa/459487/gardel-lavoz-que-cantar-225-eternamente.html. 
LATORRE, J. MONTOYA, M. MUÑOZ, J. y VÁSQUEZ, M. (2008). Evolución histórica del radioperiodismo en Antioquia en Revista Lasallista de Investigación (No. 5). Corporación Universitaria Lasallista, pp. 51-60.

LÓPEZ, J. (2000). Manual urgente para radialistas apasionados. Quito, Ecuador: Editorial Pablo de la Torriente.

PÁRAMO, C., Y LARA, A. (Productores). (2012). Historias de onda larga: memorias de la radio en Colombia. [Audio en podcast]. Recuperado de http://www.senalmemoria.co/articulos/historias-de-onda-larga-memorias-de-laradio-en-colombia.

PAREJA, R. (1984). Historia de la radio en Colombia 1929 - 1980. Bogotá, Colombia: Servicio Colombiano de Comunicación Social.

RADIO NACIONAL DE COLOMBIA. (1946). Noticias audio 2 [Audio en podcast]. Bogotá, Colombia: Señal Memoria.

RADIO NACIONAL DE COLOMBIA. (1946). Comentarios de la prensa en el conflicto petrolero [Audio en podcast]. Bogotá, Colombia: Señal Memoria.

RADIO NACIONAL DE COLOMBIA. (1947). Discurso del periodista Benítez Lumbrera acerca de los medios de comunicación Audio 2 [Audio en podcast]. Bogotá, Colombia: Señal Memoria.

RAMÍREZ, M \& TÉLLEZ, J. (2006). La educación primaria y secundaria en Colombia en el siglo XX. Bogotá, Colombia: Banco de la República.

RINCÓN, O. (2010). El Transistor. La democratización del acceso a la información en Arcadia (No. 56), p. 19.

ROCA, M. (2014). Volando sobre la ruta de los vapores: los comienzos de Scadta, 1919 1930 en Revista Confidencial (No. 290). Recuperado de http://www.banrepcultural.org/blaavirtual/revistas/credencial/febrero2014/volando-magdalena.

SANTOS, E. (2006). El día en que mataron a Gaitán en Revista Confidencial (No. 195). Recuperado http://www.banrepcultural.org/blaavirtual/revistas/credencial/marzo2006/abril. htm

SUBGERENCIA CULTURAL DEL BANCO DE LA REPÚBLICA. (2015). El periodismo en Colombia. http://www.banrepcultural.org/blaavirtual/ayudadetareas/comunicacion/el_per iodismo 
TÉLLEZ, H. (1974). Cincuenta años de radiodifusión colombiana. Bogotá, Colombia: Editorial Bedout S.A.

URIBE, D. (2019). Radio informativa y deportiva [Audio en podcast]. Recuperado de https://www.dianauribe.fm/historia-de-la-radio/10

VELÁSQUEZ, F. (2007). Orígenes del periodismo radial en Antioquia en Boletín Cultural y Biográfico, (No. 74), pp. 2-11. 